8. Schvarcz, E., et al. 1997. Physiological hyperglycemia slows gastric emptying in normal subjects and patients with insulin-dependent diabetes mellitus. Gastroenterology. 113:60-66.

9. Ceriello, A. 2005. Postprandial hyperglycemia and diabetes complications: is it time to treat? Diabetes. $54: 1-7$

10. Schmidt, R.E. 2002. Neuropathology and pathogenesis of diabetic autonomic neuropathy. Int. Rev Neurobiol. 50:257-292.

11. Cai, F., and Helke, C.J. 2003. Abnormal PI3 kinase/ Akt signal pathway in vagal afferent neurons and vagus nerve of streptozotocin-diabetic rats. Brain Res. Mol. Brain Res. 110:234-244.

12. Schmidt, R.E., Plurad, S.B., Olack, B.J., and Scharp, D.W. 1983. The effect of pancreatic islet transplantation and insulin therapy on experimental diabetic autonomic neuropathy. Diabetes. 32:532-540.

13. Fregonesi, C.E., Miranda-Neto, M.H., Molinari, S.L., and Zanoni, J.N. 2001. Quantitative study of the myenteric plexus of the stomach of rats with streptozotocin-induced diabetes. Arq. Neuropsiquiatr. 59:50-53.

14. Furlan, M.M., Molinari, S.L., and Miranda Neto, M.H. 2002. Morphoquantitative effects of acute diabetes on the myenteric neurons of the proximal colon of adult rats. Arq. Neuropsiquiatr. 60:576-581.

15. Ordog, T., Takayama, I., Cheung, W.K., Ward, S.M and Sanders, K.M. 2000. Remodeling of networks of interstitial cells of Cajal in a murine model of diabetic gastroparesis. Diabetes. 49:1731-1739.
16. Watkins, C.C., et al. 2000. Insulin restores neuronal nitric oxide synthase expression and function that is lost in diabetic gastropathy. J. Clin. Invest. 106:373-384

17. Horvath, V.J., Vittal, H., and Ordog, T. 2005. Reduced insulin and IGF-I signaling, not hyperglycemia, underlies the diabetes-associated depletion of interstitial cells of Cajal in the murine stomach. Diabetes. 54:1528-1533.

18. Anitha, M., et al. 2006. GDNF rescues hyperglycemia-induced diabetic enteric neuropathy through activation of the PI3K/Akt pathway. J. Clin. Invest. 116:344-356. doi:10.1172/JCI26295.

19. Yoshida, M.M., Schuffler, M.D., and Sumi, S.M. 1988. There are no morphologic abnormalities of the gastric wall or abdominal vagus in patients with diabetic gastroparesis. Gastroenterology. 94:907-914.

20. Tougas, G., Hunt, R.H., Fitzpatrick, D., and Upton, A.R. 1992. Evidence of impaired afferent vagal function in patients with diabetes gastroparesis. Pacing Clin. Electrophysiol. 15:1597-1602.

21. Hosking, D.J., Moody, F., Stewart, I.M., and Atkinson, M. 1975. Vagal impairment of gastric secretion in diabetic autonomic neuropathy. Br. Med. J. 2:588-590.

22. Forster, J., et al. 2005. Absence of the interstitial cells of Cajal in patients with gastroparesis and correlation with clinical findings. J. Gastrointest. Surg. 9:102-108.

23. He, C.L., et al. 2001. Loss of interstitial cells of cajal and inhibitory innervation in insulin-dependent diabetes. Gastroenterology. 121:427-434

24. Nakahara, M., et al. 2002. Deficiency of KIT-positive cells in the colon of patients with diabetes mellitus. J. Gastroenterol. Hepatol. 17:666-670.

25. Samsom, M., et al. 1998. Proximal gastric motor activity in response to a liquid meal in type 1 diabetes mellitus with autonomic neuropathy. Dig. Dis. Sci. 43:491-496

26. Mearin, F., Camilleri, M., and Malagelada, J.R. 1986. Pyloric dysfunction in diabetics with recurrent nausea and vomiting. Gastroenterology. 90:1919-1925.

27. Camilleri, M., and Malagelada, J.R. 1984. Abnormal intestinal motility in diabetics with the gastroparesis syndrome. Eur. J. Clin. Invest. 14:420-427.

28. Fraser, R., Horowitz, M., Maddox, A., and Dent, J. 1993. Organization of antral, pyloric and duodenal motility in patients with gastroparesis. J. Gastrointest. Motil. 5:167-175.

29. Ejskjaer, N.T., et al. 1999. Novel surgical treatment and gastric pathology in diabetic gastroparesis. Diabet. Med. 16:488-495.

30. Dishy, V., et al. 2004. The effect of sildenafil on gastric emptying in patients with end-stage renal failure and symptoms of gastroparesis. Clin. Pharmacol. Ther. 76:281-286.

31. Young, A.A., and Edwards, G.L. 2004. Effects of diabetes mellitus on gastrointestinal function in animal models. In Gastrointestinal function in diabetes mellitus. M. Horowitz and M. Samsom, editors. John Wiley and Sons Ltd. Chichester, United Kingdom. 29-95

\title{
Insulin's effect on the liver: "Direct or indirect?" continues to be the question
}

\author{
Jean Girard \\ Institut Cochin, Département Endocrinologie, Métabolisme et Cancer, UMR 8104 CNRS, U 567 INSERM, Université René Descartes, \\ Faculté de Médecine, Paris, France.
}

\begin{abstract}
Previous studies suggest that insulin can inhibit hepatic glucose production (HGP) by both direct and indirect actions. The indirect effects include inhibition of glucagon secretion, reduction in plasma nonesterified fatty acid levels, reduction of the amount of gluconeogenic precursor supplied to the liver, and change in neural input to the liver. A study in this issue of the JCI demonstrates that, in overnight-fasted dogs, an acute, selective increase of portal insulin induces a rapid inhibition of HGP, and a 4-fold rise in head insulin level does not enhance the inhibition of HGP in response to portal insulin infusion (see the related article beginning on page 521). This study demonstrates that insulin's direct effects on the liver dominate the control of HGP. These data balance previous studies in mice that suggested that indirect effects of insulin via the hypothalamus are the primary determinant of HGP.
\end{abstract}

\section{Introduction}

For a long time it was believed that the inhibition of hepatic glucose production (HGP) by insulin resulted only from a

Nonstandard abbreviations used: HGP, hepatic glucose production.

Conflict of interest: The author has declared that no conflict of interest exists.

Citation for this article: $J$. Clin. Invest. 116:302-304 (2006). doi:10.1172/JCI27743. direct effect of the hormone on the liver. However, 2 observations challenged this view: (a) whereas insulin is a potent inhibitor of HGP in vivo, the hormone is relatively ineffective in vitro in rodent liver (1), suggesting that insulin primarily acts on an extrahepatic tissue; and (b) peripheral insulin infusion in humans and dogs is just as effective as intraportal insulin infusion in suppressing HGP (2-4), suggesting that insulin can inhibit HGP by both direct and indirect actions (reviewed in ref. 5).

\section{Indirect action of insulin on HGP}

The indirect effects of insulin on HGP could be explained by its actions on pancreatic $\alpha$ cells, adipose tissue, and skeletal muscles. Insulin inhibits glucagon secretion from pancreatic $\alpha$ cells, thereby decreasing $\operatorname{HGP}(6,7)$. Adipose tissue and muscles are exquisitely sensitive to the inhibitory effect of insulin on lipolysis and proteolysis. Insulin induces a decrease in the release of nonesterified fatty acids and glycerol from adipose tissue (8) and gluconeogenic precursors from skeletal muscles (9), thus causing a decrease in hepatic gluconeogenesis. More recently, insulin action on the brain has been demonstrated to play a role in the regulation of HGP (10): infusion of insulin in the third cerebral ventricle of rats reduces HGP. The blockade of insulin receptors in the rodent hypothalamus (by injection of antisense oligonucleotides that 
inhibit insulin receptor expression) impairs the ability of insulin to inhibit HGP (11).

\section{Direct and dominant action of insulin on HGP}

The best in vivo demonstration of a direct effect of insulin on HGP comes from studies in overnight-fasted dogs in which changes in portal plasma insulin, in the absence of changes in plasma glucagon, nonesterified fatty acid, or gluconeogenic precursors, effectively inhibit HGP (12). The study reported by Edgerton et al. in this issue of the JCI confirms these data and demonstrates that insulin's direct effects on the liver dominate the control of HGP in overnight-fasted dogs (13). In addition, the authors show that a 4-fold rise in head insulin level does not enhance the inhibition of HGP in response to portal insulin infusion. The importance of the insulin receptor for the direct actions of insulin on HGP was supported by the observation that, in liver-specific insulin receptor knockout (LIRKO) mice, high-dose insulin fails to suppress HGP (14), but these results have been questioned, since the long-term absence of the insulin receptor may have induced an adaptive phenotype. This was supported by the finding that even upon restoration of insulin receptors to the livers of LIRKO mice, insulin was not able to suppress HGP (15). This led to the conclusion that both the direct and the indirect effects of insulin on HGP require an intact insulin-signaling pathway in liver.

\section{How do we reconcile the investigations performed in rodents and in dogs?}

It is now widely accepted that insulin inhibits HGP by both direct and indirect pathways (5), but controversy remains concerning which pathway exerts the dominant effect. In this issue of the JCI, Edgerton and colleagues provide convincing evidence that the direct effects of insulin on HGP are dominant in overnight-fasted dogs and that the indirect effects of insulin on the brain are of minor importance (13). In contrast, Rossetti and coworkers $(10,16)$ have provided robust evidence to support the existence of an indirect effect of insulin on HGP via the hypothalamus. Recently, a number of methodological and physiological considerations have been proposed to underlie the apparent complexity of insulin's observed actions on HGP (5). In particular, basal HGP is $10-15$ times greater (per kilogram of body weight) in mice than in dogs, while plasma glucagon levels are similar. It is possible that, in mice, the liver does have substantial neural input in the basal state and the removal of hepatic insulin receptors leads to increased neural control of HGP as a protective response. Another possible explanation is that, in overnight-fasted dogs, hepatic gluconeogenesis (as opposed to hepatic glycogenolysis) contributes to less than 50\% of HGP, whereas it contributes to approximately $80-90 \%$ of HGP in rodents. In mice fasted for 4 hours and 24 hours, hepatic glycogenolysis contributed to less than $10-20 \%$ of HGP (17). As hepatic gluconeogenesis is much less sensitive to inhibition by insulin than glycogenolysis (18), it could be suggested that, in mice, efficient inhibition of hepatic gluconeogenesis by insulin requires basal inputs from the CNS. Several lines of evidence suggest that an autonomic neural input to the liver can modulate liver metabolism $(19,20)$. When insulin levels are increased via a systemic insulin infusion, the activation of central ATP-dependent potassium channels is required for the inhibition of HGP (16). It has been suggested that descending fibers within the hepatic branch of the vagus nerve could vehiculate autonomic neural input to the liver to modulate liver metabolism. Indeed, the inhibition of central fat oxidation, which, like insulin infusion, inhibits HGP, is largely accounted for by a marked inhibition of gluconeogenesis (21). Furthermore, hepatic vagotomy abolishes the effects of inhibition of central fat oxidation on HGP (21). It could be of interest to investigate whether the inhibition of HGP in response to insulin infusion is due to an inhibition of gluconeogenesis and whether hepatic vagotomy abolishes this effect.

It is possible that in overnight-fasted dogs, acute changes in plasma insulin have a predominantly direct effect on glycogenolysis, whereas at later time points insulin may inhibit gluconeogenesis by a predominantly indirect mechanism (secondary to an inhibition of lipolysis in adipose tissue and of proteolysis in skeletal muscle, which reduces the amount of FFAs, glycerol, and amino acids reaching the liver; see ref. 12).

\section{Concluding remarks}

The relative importance of direct and/or indirect effects of insulin on HGP could have implications for diabetes treatment. Indeed, the enhanced HGP observed in type 2 diabetes patients is primarily due to an increase in gluconeogenesis (22).
As gluconeogenesis is much less sensitive than glycogenolysis to the inhibition by insulin, hepatic insulin resistance observed in type 2 diabetics could be due simply to the enhanced gluconeogenesis and not necessarily to a defect in insulin signaling. If this is true, a rational therapeutic approach for the correction of HGP in type 2 diabetes would be an inhibition of gluconeogenesis. Plasma glucagon levels are increased throughout the day in type 2 diabetic patients despite hyperglycemia (23), and glucagon stimulates gluconeogenic enzyme gene expression (24). This could explain the predominance of this pathway in the liver of type 2 diabetics. Recently, it has been shown that glucagon-like peptide1 , in addition to its well-known effect on the stimulation of insulin secretion, was able to inhibit glucagon secretion (25). This molecule could have promising effects for the treatment of increased HGP seen in type 2 diabetes.

Address correspondence to: Jean Girard, Institut Cochin, Département Endocrinologie, Métabolisme et Cancer, UMR 8104 CNRS, U 567 INSERM, Université René Descartes, Faculté de Médecine Cochin, 24 rue du Faubourg Saint-Jacques, 75014 Paris, France. Phone: 33-153-73-27-00; Fax: 33-15373-27-01; E-mail: girard@cochin.inserm.fr.

1. Williamson, J., Wright, P., Malaisse, W., and Ashmore, J. 1966. Control of gluconeogenesis by acetyl $\mathrm{CoA}$ in rats treated with glucagon and anti-insulin serum. Biochem. Biophys. Res. Commun. 22:765-770.

2. Ader, M., and Bergman, R. 1990. Peripheral effects of insulin dominate suppression of fasting hepatic glucose production. Am. J. Physiol. 258:E1020-E1032.

3. Giacca, A., et al. 1992. Importance of peripheral insulin levels for insulin-induced suppression of glucose production in depancreatized dogs. J. Clin. Invest. 90:1769-1777.

4. Lewis, G.F., Zinman, B., Groenewoud, Y., Vranic, M., and Giacca, A. 1996. Hepatic glucose production is regulated both by direct hepatic and extrahepatic effects of insulin in humans. Diabetes. 45:454-462.

5. Cherrington, A.D. 2005. The role of hepatic insulin receptors in the regulation of glucose production. J. Clin. Invest. 115:1136-1139. doi:10.1172/ JCI200525152.

6. Ishihara, H., Maechler, P., Gjinovci, A., Herrera, P.L., and Wollheim, C.B. 2003. Islet $\beta$-cell secretion determines glucagon release from neighbouring alpha-cells. Nat. Cell Biol. 5:330-335.

7. Diao, J., Asghar, Z., Chan, C.B., and Wheeler, M.B. 2005. Glucose-regulated glucagon secretion requires insulin receptor expression in pancreatic alpha-cells. J. Biol. Chem. 280:33487-33496.

8. Sindelar, D.K., et al. 1997. The role of fatty acids in mediating the effects of peripheral insulin on hepatic glucose production in the conscious dog. Diabetes. 46:187-196.

9. Sindelar, D.K., Balcom, J.H., Chu, C.A., Neal, D.W., and Cherrington, A.D. 1996. A comparison of the effects of selective increases in peripheral or portal insulin on hepatic glucose production in the conscious dog. Diabetes. 45:1594-1604. 
10. Obici, S., Feng, Z., Karkanias, G., Baskin, D.G., and Rossetti, L. 2002. Decreasing hypothalamic insulin receptors causes hyperphagia and insulin resistance in rats. Nat. Neurosci. 5:566-572.

11. Buettner, C., et al. 2005. Severe impairment in liver insulin signaling fails to alter hepatic insulin action in conscious mice. J. Clin. Invest. 115:1306-1313. doi:10.1172/JCI200523109.

12. Cherrington, A. 1999. Control of glucose uptake and release by the liver in vivo. Diabetes. 48:1198-1214.

13. Edgerton, D.S., et al. 2006. Insulin's direct effects on the liver dominate the control of hepatic glucose production. J. Clin. Invest. 116:521-527. doi:10.1172/JCI27073.

14. Fisher, S.J., and Kahn, C.R. 2003. Insulin signaling is required for insulin's direct and indirect action on hepatic glucose production. J. Clin. Invest. 111:463-468. doi:10.1172/JCI200316426.

15. Okamoto, H., Obici, S., Accili, D., and Rossetti, L. 2005. Restoration of liver insulin signaling in Insr knockout mice fails to normalize hepatic insulin action. J. Clin. Invest. 115:1314-1322. doi:10.1172/ JCI200523096.

16. Obici, S., Zhang, B.B., Karkanias, G., and Rossetti, L. 2002. Hypothalamic insulin signaling is required for inhibition of glucose production. Nat. Med. 8:1376-1382.

17. Burgess, S.C., et al. 2005. Effect of murine strain on metabolic pathways of glucose production after brief or prolonged fasting. Am. J. Physiol. 289:E53-E61.

18. Chiasson, J.L., Liljenquist, J.E., Finger, F.E., and Lacy, W.W. 1976. Differential sensitivity of glycogenolysis and gluconeogenesis to insulin infusion in dogs. Diabetes. 25:283-291.

19. Shimazu, T. 1987. Neuronal regulation of hepatic glucose metabolism in mammals. Diabetes Metab. Rev. 3:185-206.

20. Jungermann, K., et al. 1987. Regulation of liver metabolism by hepatic nerves. Adv. Enzyme Regul. 26:63-88.
21. Pocai, A., Obici, S., Schwartz, G., and Rossetti, L. 2005. A brain-liver circuit regulates glucose homeostasis. Cell Metab. 1:53-61.

22. Magnusson, I., Rothman, D.L., Katz, L.D., Shulman, R.G., and Shulman, G.I. 1992. Increased rate of gluconeogenesis in type-II diabetes-mellitus. A ${ }^{13} \mathrm{C}$ nuclear magnetic resonance study. J. Clin. Invest. 90:1323-1327.

23. Reaven, G.M., Chen, Y.D.I., Golay, A., Swislocki, A.L., and Jaspan, J.B. 1987. Documentation of hyperglucagonemia throughout the day in nonobese and obese patients with non-insulin-dependent diabetes mellitus. J. Clin. Endocrinol. Metab. 64:106-110.

24. Granner, D.K., and Pilkis, S.J. 1990. The genes of hepatic glucose metabolism. J. Biol. Chem. 265:10173-10176.

25. Drucker, D.J. 2002. Biologic actions and therapeutic potential of the proglucagon-derived peptides. Gastroenterology. 122:531-544.

\title{
C5a and Fcy receptors: a mutual admiration society
}

\author{
John P. Atkinson
}

Washington University School of Medicine, St. Louis, Missouri, USA.

\begin{abstract}
Phagocytosis is a key process in protection of the host against pathogens and in provision of antigens for the immune response. Synergism between $\mathrm{C} 3 \mathrm{~b}$ and IgG and their receptors in promoting adherence to and then ingestion of an antigen has been recognized for decades. Only more recently, however, has cross-talk between another complement activation fragment, the anaphylatoxin $\mathrm{C5a}$, and $\mathrm{Fc} \gamma$ receptors $(\mathrm{Fc} \gamma \mathrm{Rs})$ been defined. In this issue of the JCI, C5a is shown to signal, via its receptor, the upregulation of activating (proinflammatory-type) $\mathrm{F} \gamma \gamma \mathrm{Rs}$ (see the related article beginning on page 512). Moreover, engagement of Fc $\gamma$ Rs by the IgG-bearing immune complex instructs the cell to synthesize more $\mathrm{C5}$, from which $\mathrm{C5a}$ is derived. Thus, this work establishes a feedback loop whereby $F c \gamma R$ expression and function are enhanced, a very desirable event in concert with an infection but potentially deleterious in autoimmunity.
\end{abstract}

\section{Opsonization: helping phagocytes to eat}

Opsonins attach to invading microorganisms and other antigens in order to enhance the uptake of foreign particles by phagocytes. The 2 most important opsonins in blood are Ig and complement (C). Specifically, IgG and C3b bind to a target where they serve as ligands for $\mathrm{Fc} \gamma$ and $\mathrm{C}$ receptors, respectively. This reaction can be conveniently split into 2 sequential steps; namely, immune adherence followed by internalization. Early on, it was

Nonstandard abbreviations used: C, complement; $\mathrm{C} 5 \mathrm{aR}, \mathrm{C} 5 \mathrm{a}$ anaphylatoxin receptor; $\mathrm{Fc} \gamma \mathrm{R}, \mathrm{F} \gamma \gamma$ receptor.

Conflict of interest: The author has declared that no conflict of interest exists.

Citation for this article: J. Clin. Invest. 116:304-306 (2006). doi:10.1172/JCI27759. recognized that $\mathrm{C} 3 \mathrm{~b}$ and $\mathrm{C}$ receptors most effectively mediated the adherence step, while $\mathrm{Fc} \gamma$ receptors ( $\mathrm{F} c \gamma \mathrm{Rs}$ ) most effectively mediated the internalization step. This combination of "talents" ensures efficient phagocytosis of an infectious particle. As the humoral immune response rapidly matures, it deposits more and more IgG on particles, which subsequently elicits complement activation.

Many types of in vivo and in vitro experiments have demonstrated how much more proficient $\mathrm{C} 3 \mathrm{~b}$ and $\mathrm{IgG}$ are as partners than either is alone in promoting phagocytosis. C3b can mediate internalization but requires a relatively large ligand load and activated monocytes/macrophages. IgG can mediate adherence, but again, a heavy dose of ligand is necessary. However, a com- bination of C3b and IgG is synergistic in mediating the phagocytic process. Thus, this cooperation between the receptors for these 2 ligands enhances this time-honored immune phenomenon that is critical to survival. In this issue of the JCI, Kumar, Gessner, and colleagues provide further evidence for another remarkable interaction among complement-derived ligands, Igs, and their receptors (1).

\section{Cross-talk between C5a and Fc $\gamma$ Rs}

Kumar et al. (1) report a clear demonstration of cross-talk between the C and Ig receptors (Figure 1 and Table 1 ). In a mouse model of a so-called antibody-dependent, type II autoimmune reaction, the authors convincingly demonstrate the following interesting sequence of events: (a) upon injection of an autoantibody to mouse rbcs, immune complexes form that bind to Fc $\gamma$ Rs on liver macrophages (Kupffer cells); (b) these cells in turn secrete C5 and possibly a protease (yet to be clearly defined) that cleaves $\mathrm{C} 5$ into the anaphylatoxin $\mathrm{C} 5 \mathrm{a}$ and the initiator of membrane attack complex, C5b; (c) C5a binds to its receptor (C5aR) on Kupffer cells, which upregulates Fc $\gamma R$ mRNA expression; and then (d) the increased number of Fc $\gamma$ Rs on these macrophages facilitates elimination of the antibody-coated rbcs, thereby leading to a more severe hemolytic anemia. While this 